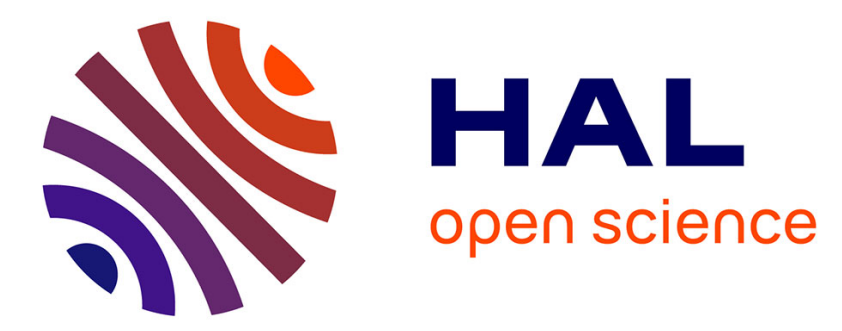

\title{
A phenomenological approach of solidification of polymeric phase change materials
}

S. Amir Bahrani, Laurent Royon, Bérangère Abou, Rémy Osipian, Kamel Azzouz, André Bontemps

\section{- To cite this version:}

S. Amir Bahrani, Laurent Royon, Bérangère Abou, Rémy Osipian, Kamel Azzouz, et al.. A phenomenological approach of solidification of polymeric phase change materials. Journal of Applied Physics, 2017, 121 (3), pp.035103. 10.1063/1.4974287 . hal-01473545

\section{HAL Id: hal-01473545 \\ https://hal.science/hal-01473545}

Submitted on 27 Feb 2017

HAL is a multi-disciplinary open access archive for the deposit and dissemination of scientific research documents, whether they are published or not. The documents may come from teaching and research institutions in France or abroad, or from public or private research centers.
L'archive ouverte pluridisciplinaire HAL, est destinée au dépôt et à la diffusion de documents scientifiques de niveau recherche, publiés ou non, émanant des établissements d'enseignement et de recherche français ou étrangers, des laboratoires publics ou privés.

\section{(c)(1)}

Distributed under a Creative Commons Attribution| 4.0 International License 


\section{A phenomenological approach of solidification of polymeric phase change materials}

Seyed Amir Bahrani, Laurent Royon, Bérengère Abou, Rémy Osipian, Kamel Azzouz, and André Bontemps

Citation: J. Appl. Phys. 121, 035103 (2017); doi: 10.1063/1.4974287

View online: http://dx.doi.org/10.1063/1.4974287

View Table of Contents: http://aip.scitation.org/toc/jap/121/3

Published by the American Institute of Physics

\section{Articles you may be interested in}

Long-range Tamm surface plasmons supported by graphene-dielectric metamaterials

J. Appl. Phys. 121, 033101033101 (2017); 10.1063/1.4973900 


\title{
A phenomenological approach of solidification of polymeric phase change materials
}

\author{
Seyed Amir Bahrani, ${ }^{1, a)}$ Laurent Royon, ${ }^{2}$ Bérengère Abou, ${ }^{1}$ Rémy Osipian, ${ }^{1}$ \\ Kamel Azzouz, ${ }^{3}$ and André Bontemps ${ }^{2}$ \\ ${ }^{1}$ Université Paris Diderot, Sorbonne Paris Cité, MSC, UMR 7057 CNRS, 75013 Paris, France \\ ${ }^{2}$ Université Paris Diderot, Sorbonne Paris Cité, LIED, UMR 8236 CNRS, 75013 Paris, France \\ ${ }^{3}$ Valeo Thermal Systems, 78321 La Verrière, France
}

(Received 18 October 2016; accepted 2 January 2017; published online 19 January 2017)

\begin{abstract}
Phase Change Materials (PCMs) are widely used in thermal energy storage and thermal management systems due to their small volume for a given stored energy and their capability for maintaining nearly constant temperatures. However, their performance is limited by their low thermal conductivity and possible leaks while in the liquid phase. One solution is to imprison the PCM inside a polymer mesh to create a Polymeric Phase Change Material (PPCM). In this work, we have studied the cooling and solidification of five PPCMs with different PCMs and polymer fractions. To understand the heat transfer mechanisms involved, we have carried out micro- and macrorheological measurements in which Brownian motion of tracers embedded in PPCMs has been depicted and viscoelastic moduli have been measured, respectively. Beyond a given polymer concentration, it was shown that the Brownian motion of the tracers is limited by the polymeric chains and that the material exhibits an elastic behavior. This would suggest that heat transfer essentially occurs by conduction, instead of convection. Experiments were conducted to measure temperature variation during cooling of the five samples, and a semi-empirical model based on a phenomenological approach was proposed as a practical tool to choose and size PPCMs. Published by AIP Publishing. [http://dx.doi.org/10.1063/1.4974287]
\end{abstract}

\section{INTRODUCTION}

With the rapid growth of energy needs, energy storage has become a strong concern. In thermal power plants, up to $70 \%$ of thermal energy is released to the environment. Renewable energies, such as solar or wind, are intermittent and can therefore not always match consumer needs. Thermal energy storage is a possible solution (i) to use the thermal energy lost in power plants and (ii) to store energy when in excess and deliver it when needed. At the same time, electricity consumption varies strongly during day and night due to domestic utilities and space heating/cooling, leading to peak and off-peak load periods. Thermal storage could be a way to store energy during off-peak periods to release it during peak periods. Among thermal storage methods, ${ }^{1}$ latent heat storage has received most attention because volume requirements are lower than sensible heat storage, and most investigations are based on the use of Phase Change Materials (PCMs). In addition, PCMs can be applied to stabilize component temperatures due to their constant phase-change temperature.

However, PCMs have some well-known disadvantages. The first of these is super-cooling. This refers to the PCM cooling below its solidification temperature without solidifying. In order to do so, a lower temperature must be reached. Generally, this effect is weak for organic materials, and the difference of equilibrium and actual solidification

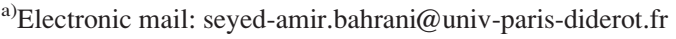

temperature is small. Second, phase separation can occur for PCMs that are mixtures. Third, most PCMs have low thermal conductivity, which impedes heat transfer. Finally, an important practical problem is that of PCM conditioning, which must prevent leaking when the PCM is liquid.

To overcome the preceding problems, two types of solutions can be proposed: (i) incorporation of PCMs in macro-, micro-, or nano-capsules or (ii) creation of a composite material by embedding the PCMs within a matrix. In the first case, PCMs are incorporated inside containers ranging from $1 \mathrm{~cm}^{3}$ to several $\mathrm{m}^{3}$ or inside a polymer solid shell whose diameter varies between 0.1 and $100 \mu \mathrm{m} .^{2-4}$ In the second case, PCMs are introduced in a polymer network whose elasticity can absorb any material volume change without degradation and avoids exsudation of the PCM in the liquid state.

Both problems of low thermal conductivity and PCM leakage can be solved simultaneously. ${ }^{5,6}$ This work aims at addressing these two problems through the introduction of a polymer matrix in the PCMs. In our study, three PCMs (RT 27, n-Hexadecane, and Phytagel) were imprisoned inside a polymer fibrous structure to form five different shapestabilized PCMs or Polymeric Phase Change Materials (PPCMs). We have investigated the freezing of our PPCMs and determined their temperature evolution during the solidification phase. We have also performed microrheological and macrorheological measurements to investigate the characteristics and physical behavior of these materials. The rheology experiments show that beyond a given polymer fraction, the materials have an elastic behavior, which is 
typical of a solid-like behavior, favorable to avoiding leaks. Microrheology performed in PCMs with increasing polymer concentration provides insight into the heat transfer modes (conduction and/or convection). These characterizations have allowed us to propose a semi-empirical model based on a phenomenological approach of material cooling with the change of state, which will be a practical tool for predicting temperature evolution in PPCMs.

The paper is organized as follows. In Sec. II, the preparation of PCMs and PPCMs together with their thermophysical properties is presented. We have also described the methodology adopted for the micro/macro rheology experiments, and then in this section, the experimental set-up and the solidification procedure are defined. The experimental results of micro/macro-rheology and solidification thermograms are presented in Sec. III. Sec. IV provides our semiempirical model based on a phenomenological approach. In this section, we have determined the model parameters and their validation using previous theoretical and analytical approaches. Finally, Sec. V is devoted to a concluding discussion.

\section{MATERIALS AND CHARACTERIZATION METHODS}

\section{A. Preparation of PCMs and PPCMs}

The PCMs chosen for this study are, respectively, two paraffins: Rubitherm ${ }^{\circledR}$, n-hexadecane, and an aqueous gel called Phytagel $^{\circledR}$. Rubitherm (RT 27) and n-Hexadecane were purchased from Rubitherm $\mathrm{GmbH}$ and Sigma-Aldrich, respectively. The polymer network was obtained by using a Styrene-Butadiene-Styrene (SBS), supplied by SigmaAldrich.

The shape-stabilized paraffin (PPCM) was prepared via the following procedure: for the organic PCM, the paraffin was stirred at $100^{\circ} \mathrm{C}$ for $1 \mathrm{~h}$ to yield a homogenous solution. Then, the SBS block copolymer was mixed at high temperature $\left(\sim 100^{\circ} \mathrm{C}\right)$ with the paraffin. This PCM serves as the latent heat storage material, and the SBS block copolymer forms a matrix acting as a supporting material. After cooling at room temperature, we obtained a shape-stabilized paraffin material (PPCM). Several samples with polymer concentration from $0 \%$ to $25 \%$ (RUB $0-25$ and HEX 10) were prepared. No leakage of the paraffin was observed beyond PCM melting temperature.

The preparation of the aqueous PCM (Phytagel) was obtained by using a water-soluble polysaccharide named
Gellan gum and sodium citrate as a source of cations, supplied by Sigma-Aldrich. For aqueous PCMs, $3 \mathrm{mg}$ Gellan gum (Phytagel ${ }^{\circledR}$ ) powder was mixed into $100 \mathrm{ml}$ of a distilled water $+\mathrm{CaCl}_{2}\left(1.1 \times 10^{-2} \mathrm{~g} \mathrm{l}^{-1}\right)$ solution maintained at $85^{\circ} \mathrm{C}$ (GG 3). The mixture was stirred at $85^{\circ} \mathrm{C}$ for $15 \mathrm{~min}$ using a magnetic stirrer.

\section{B. Thermophysical properties of the PPCMs}

For each PPCM, thermophysical properties were measured. The mass density $\rho$ was measured by weighing and the thermal conductivity $\lambda$ by means of a homemade conductimeter. ${ }^{7}$ The thermodynamical properties, such as the solidification temperature $T_{s}$, melting temperature $T_{m}$, latent heat $L$, and heat capacity $C p$, were deduced from calorimetric measurements whose details are presented in the Appendix. All results are summarized in Table I.

\section{Microrheology measurements}

Passive microrheology experiments were performed for the Rubitherm (RT 27) paraffin with several polymer concentrations: $0 \%, 1 \%, 2 \%, 4 \%, 6 \%$, and $8 \%$ (in the following, we will adopt the notations: RUB 0, 1, 2, 4, 6 and 8). Latex tracer beads $(0.994 \mu \mathrm{m}$ in diameter $)$ were introduced in the samples, and their thermal fluctuations were recorded with a fast camera (EoSens Mikrotron). The camera, typically running at 100 frames per second (fps), is coupled to an inverted microscope (Leica DM IRB) with a $100 \times$ oil immersion objective. The microscope objective temperature, controlled within $0.1^{\circ} \mathrm{C}$ using a Bioptechs heating ring, was maintained at $32.0^{\circ} \mathrm{C}$. The sample temperature was controlled through the immersion oil in contact. The tracer concentration chosen was diluted enough to prevent collisions and hydrodynamic coupling. They were always tracked far enough from the walls of the observation chamber. Sedimentation of the beads was negligible on the recording time scales. Homemade image analysis software allowed us to track the bead positions $x(t)$ and $y(t)$ close to the focus plane of the objective. For each bead, the time-averaged mean-squared displacement (MSD) was calculated and ensemble-averaged over several beads. ${ }^{8}$

\section{Macrorheology measurements}

To quantify the mechanical properties of PPCMs, linear rheology experiments were performed, using a Physica MCR

TABLE I. Thermophysical properties of PPCMs.

\begin{tabular}{|c|c|c|c|c|c|c|c|c|c|}
\hline \multirow[b]{2}{*}{ Sample } & \multirow[b]{2}{*}{$T_{s}\left({ }^{\circ} \mathrm{C}\right)$} & \multirow[b]{2}{*}{$T_{m}\left({ }^{\circ} \mathrm{C}\right)$} & \multicolumn{2}{|c|}{$\rho\left(\mathrm{kg} \mathrm{m}^{-3}\right)$} & \multicolumn{2}{|c|}{$\lambda\left(\mathrm{Wm}^{-1} \mathrm{~K}^{-1}\right)$} & \multicolumn{2}{|c|}{$C p\left(\mathrm{~kJ} \mathrm{~kg}^{-1} \mathrm{~K}^{-1}\right)$} & \multirow[b]{2}{*}{$L\left(\mathrm{~kJ} \mathrm{~kg}^{-1}\right)$} \\
\hline & & & Solid $^{\mathrm{a}}$ & Liquid $^{\mathrm{b}}$ & Solid & Liquid & Solid & Liquid & \\
\hline RUB 15 & 22.6 & 27 & 856.9 & 776 & 0.28 & 0.19 & 1.98 & 2.03 & 127.5 \\
\hline RUB 20 & 22.0 & 27 & 856.3 & 790 & 0.26 & 0.18 & 3.9 & 2.30 & 100 \\
\hline RUB 25 & 21.5 & 27 & 855.7 & 805 & 0.24 & 0.16 & 5.8 & 2.50 & 80 \\
\hline HEX 10 & 13.6 & 18 & 783 & 766 & 0.34 & 0.14 & 1.8 & 2.3 & 235 \\
\hline GG 3 & 0.1 & 0.7 & 917 & 1000.4 & 0.22 & 0.57 & 2.02 & 4.2 & 333 \\
\hline
\end{tabular}

${ }^{\mathrm{a}}$ The temperature of PPCMs in the solid phase: RUB 15,20 , and $25=40^{\circ} \mathrm{C}$; HEX $10=5^{\circ} \mathrm{C}$; and GG $3=-5^{\circ} \mathrm{C}$.

${ }^{\mathrm{b}}$ The temperature of PPCMs in the liquid phase: RUB 15,20 , and $25=19^{\circ} \mathrm{C}$; $\operatorname{HEX~} 10=30^{\circ} \mathrm{C}$; and GG $3=5^{\circ} \mathrm{C}$. 
500 rheometer (Anton Paar) in the cone-plate geometry $\left(50 \mathrm{~mm}\right.$ diameter with $1^{\circ}$ cone angle). Prior to the measurements, a strain sweep test was conducted to determine the linear viscoelastic strain range. The rheological behavior of each sample was measured by performing a temperature sweep. The temperature dependence of storage $\left(G^{\prime}\right)$ and loss $\left(G^{\prime \prime}\right)$ moduli, as well as loss tangent $(\tan \delta)$, were measured by heating the sample from $20^{\circ} \mathrm{C}$ to $85^{\circ} \mathrm{C}$. The gradient was $1{ }^{\circ} \mathrm{C} / \mathrm{mn}$ on heating and cooling scans. The frequency $f$ was fixed at $1 \mathrm{~Hz}$ and strain $\gamma$ of $1 \%$, which corresponds to the linear viscoelastic region for all the samples. The melting temperature was taken as the point for which both $G^{\prime}$ and $G^{\prime \prime}$ moduli decrease sharply. The temperature $T_{g}$ where $\tan \delta=1$ (i.e., $G^{\prime}=G^{\prime \prime}$ ) was defined as the temperature of hard gelsoft gel transition.

\section{E. Set-up and solidification procedure}

Heat transfer experiments involving solidification were conducted with a test cell presented in Figure 1. The cell consists of a parallelepipedic sample of PPCMs with a square section of $0.25 \mathrm{~cm}^{2}$ and length $E=1 \mathrm{~cm}$, insulated with $100 \mathrm{~mm}$ thick polyurethane foam. Only one side of the sample $\left(0.25 \mathrm{~cm}^{2}\right)$ is in contact with the ambient air. The insulated material around the PPCM allows us to consider the transfers to be unidirectional inside the sample. A Chromel/Alumel thermocouple is placed on the opposite face to that in contact with the ambient air as shown in Figure 1.

The experiments were performed using the following experimental protocol. Prior to starting each solidification test, the PPCM was maintained at $T_{o}=32^{\circ} \mathrm{C}$ inside a climatic chamber. After reaching this initial condition, the experimental procedure then consisted to suddenly transfer the sample into another climatic chamber, which was maintained at temperature $T_{f}$ such that $T_{f}<T_{o}$. The temperature history was recorded by using a data logger (GL220, Graphtech, Canada) at $1 \mathrm{~s}$ intervals. All experiments were performed with the same weight $(100 \mathrm{~g})$ of PPCMs with different polymer concentrations and nature (RUB 15, 20 and 25; HEX 10; and GG 3).

\section{RESULTS AND DISCUSSION}

\section{A. Micro-rheology experiments}

Figure 2(a) shows the trajectories of a typical traced bead in pure paraffin (RUB 0) and in RUB 8 (inset), at the same scale. A zoom of the trajectory in the RUB 8 is

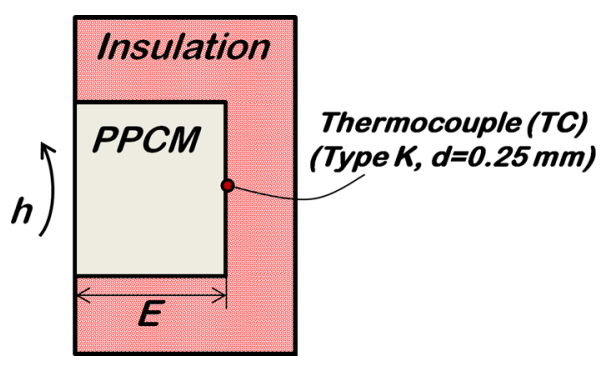

FIG. 1. Schematic of the experimental test cell.

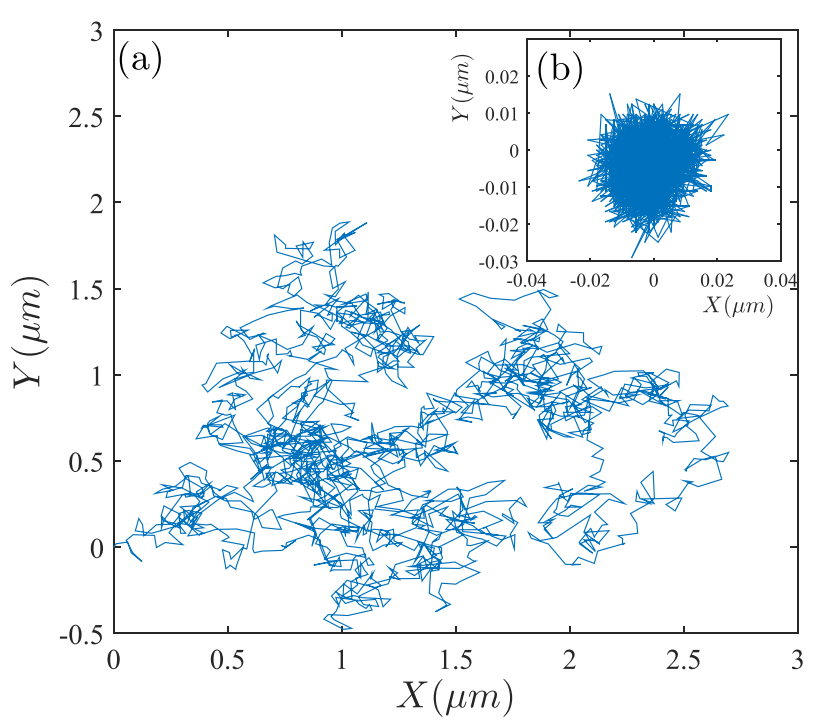

FIG. 2. (a) Trajectory of a typical Latex probe in the pure paraffin (RUB 0) and in the PPCM at $8 \%$ polymer concentration (RUB 8), represented at the same scale. (b) Zoom of the trajectory of a typical tracer in the RUB 8 PPCM. The motion of the tracer is confined in the RUB 8 PPCM as compared to pure paraffin. The confinement is more pronounced with increasing polymer concentration as can be depicted in Figure 3.

presented in Figure 2(b). As can be seen, the tracer is confined in a small space in the polymeric network contrary to pure paraffin.

Figure 3 shows the Mean-Squared Displacement (MSD), $\left\langle\Delta r^{2}(t)\right\rangle\left(\mu \mathrm{m}^{2}\right)$, of the tracers in the paraffin RT 27 with increasing polymer concentration $(0 \%, 1 \%, 2 \%, 4 \%$, $6 \%$, and $8 \%$ ). Starting from a purely viscous liquid with no additive polymer, the PPCM develops an elasticity with increasing polymer concentration. Above 6\% (RUB 6), the material is so stiff that the Brownian motion of the tracers was hardly detectable, and we reach the set-up resolution limitation.

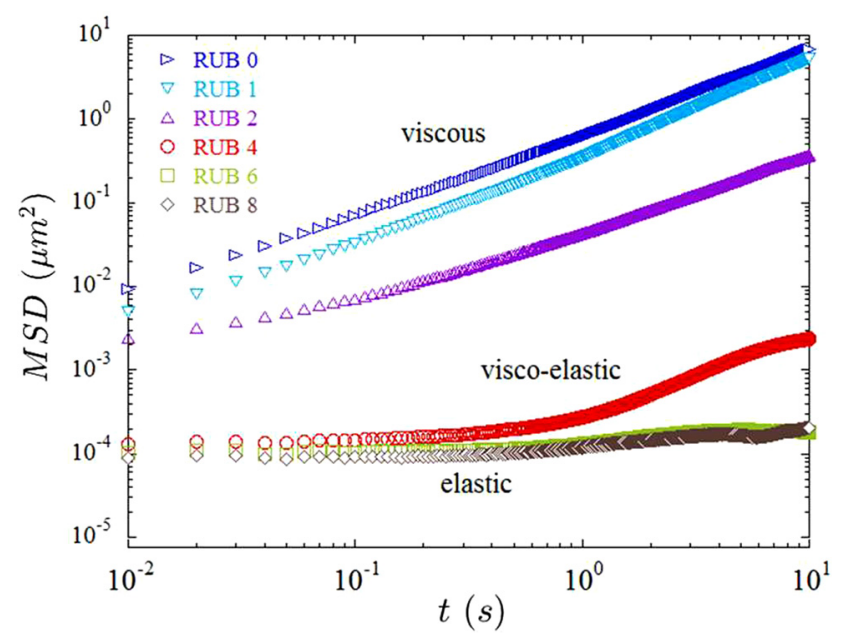

FIG. 3. Mean-squared displacement of Latex beads $(0.994 \mu \mathrm{m}$ in diameter) immersed in the paraffin RT 27 with increasing additive polymer concentration $(0 \%, 1 \%, 2 \%, 4 \%, 6 \%$, and $8 \%)$. Starting from a purely viscous liquid with no additive polymer, the PPCM develops elasticity with increasing polymer concentration. Above $6 \%$, the material is so stiff that the Brownian motion of the tracers was hardly detectable. 
Above 6\% polymer concentration, when the PPCM develops a predominant elastic behavior, one expects that heat convection is inhibited. Therefore, heat transfer inside the sample should be purely conductive. These findings justify the further hypotheses.

\section{B. Thermo-rheological properties of PPCMs}

As can be seen in Figure 4, we present the temperature dependence of viscoelastic moduli during the heating of PPCMs at different concentrations (RUB 0, 5, 10, 15, 20, and 25). The six rheograms exhibit a liquid-solid phase change around $27^{\circ} \mathrm{C}$ with an abrupt variation of storage $\left(G^{\prime}\right)$ and loss $\left(G^{\prime \prime}\right)$ moduli. At $T<27^{\circ} \mathrm{C}$, the viscoelastic moduli are large, indicating a solid phase. Above $T=27^{\circ} \mathrm{C}, G^{\prime}$ and $G^{\prime \prime}$ decrease to reach the liquid phase. As an example, the viscoelastic moduli of PPCM (RUB 15) present values around $10 \mathrm{kPa}$, which means that the polymer network allows sufficient rigidity for considering the material as a solid. With increasing temperature, a gel-liquid transition appears around $55^{\circ} \mathrm{C}$ where $G^{\prime}$ intersects $G^{\prime \prime}$. This temperature indicates the limit of its use in the field of thermal energy storage; the material becomes a viscoelastic liquid, and it cannot be used without an encapsulation.

A study of this threshold temperature, noted $T_{g}$, shows a linear dependence with the SBS polymer concentration $(\phi \%)$ as illustrated in Figure 5. The higher the SBS polymer concentration in the PPCM, the smaller risk of leakage. These results confirm the behavior found in microrheology.

\section{Temperature profile during solidification}

The experimental results are presented in terms of the dimensionless temperature $\theta$ defined as

$$
\theta=\frac{T-T_{f}}{T_{i}-T_{f}} .
$$

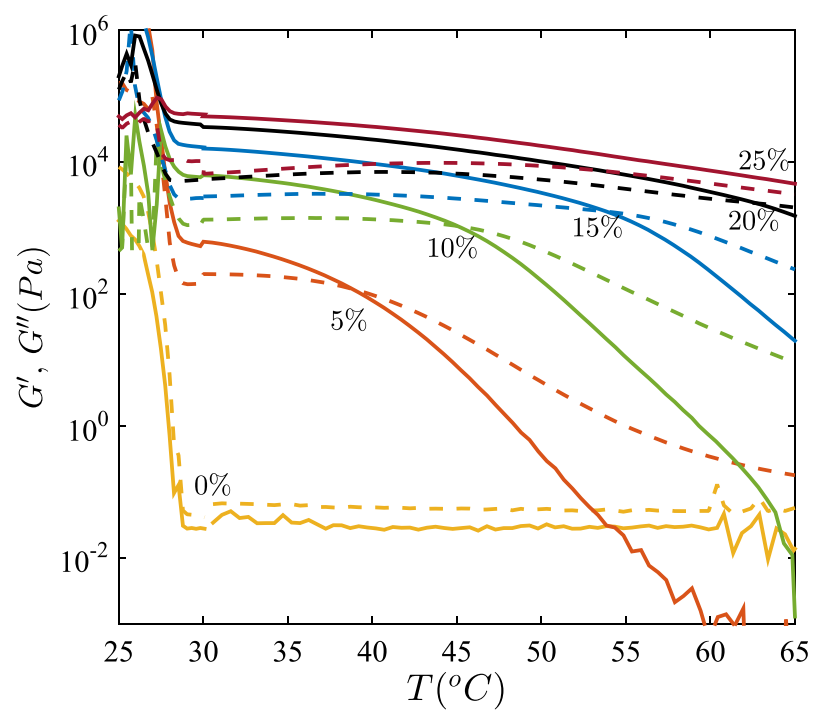

FIG. 4. Viscoelastic moduli $G^{\prime}$ (continuous line) and $G^{\prime \prime}$ (dashed line) as a function of temperature for different polymer concentrations (RUB 0, 5, 10, 15,20 , and 25).

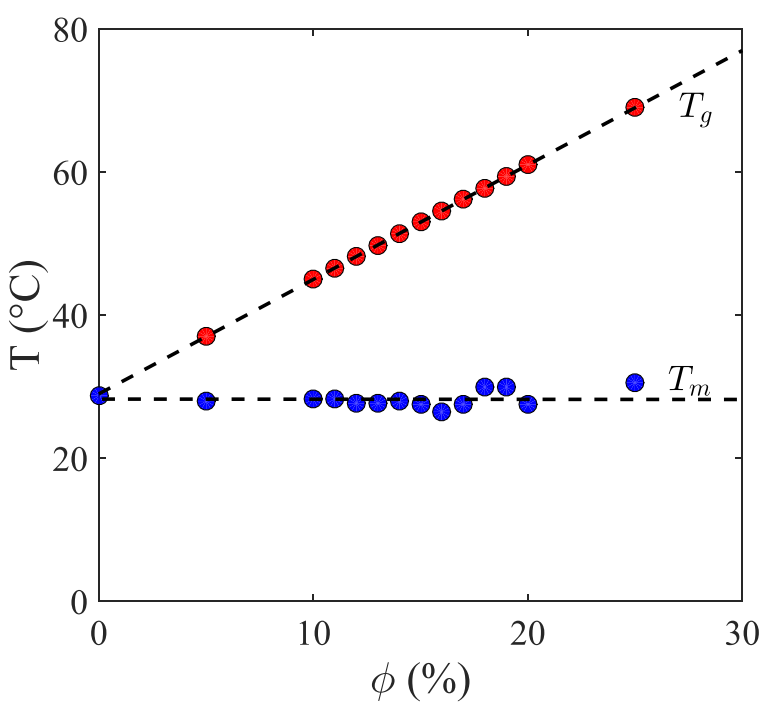

FIG. 5. Phase change solid-liquid temperature $T_{m}$ and gel-liquid temperature $T_{g}$ of PPMCs (RUBs) as a function of the SBS polymer concentration $\phi \%$.

Figure 6 presents the dimensionless temperature $\theta$ at the rear face of the sample $v s$ the time for a solidification phase. We note $\theta_{0}$ the dimensionless phase change temperature defined as

$$
\theta_{0}=\frac{T_{s}-T_{f}}{T_{i}-T_{f}} .
$$

First, the temperature strongly decreases with time in the temperature interval $1-\theta_{0}$. Then, $\theta$ stabilizes during the phase change of PPCMs presenting a pseudo-plateau at $\theta_{0}$ and rapidly decreases until it reaches the final temperature imposed by the climatic chamber. Thermograms obtained for all samples present similar curves to that illustrated in Figure 6. The distinctions of thermograms appear only by the pseudo-plateau length of temperature induced by the phase change. For all PPCMs with different concentrations, our results showed that the higher the polymer concentration

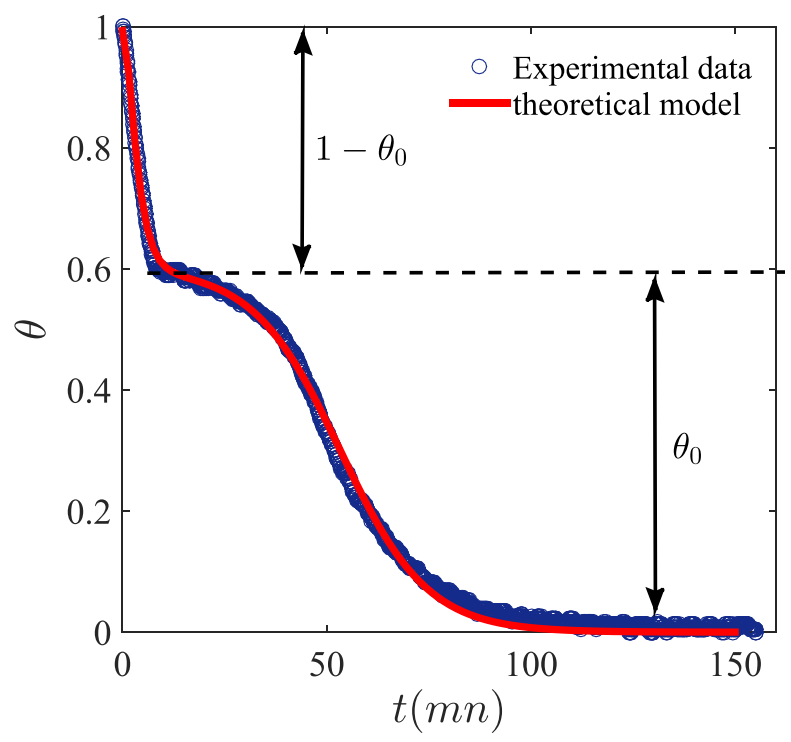

FIG. 6. Thermogram obtained from RUB 25 with $T_{f}=10^{\circ} \mathrm{C}$. 
and the lower the temperature difference $\theta_{0}$, the longer the duration of the pseudo-plateau. As an example for the case of RUB 25, Figure 7 presents the evolution of $\theta$ for several values of $\theta_{0}$ corresponding to different $T_{f}$.

\section{PHENOMENOLOGICAL APPROACH}

\section{A. Model description}

We propose to model the thermograms of our all experiments with a semi-empirical approach, by the following phenomenological expression:

$$
\theta=\frac{1}{2}\left[e^{\frac{-t}{\tau_{1}}}+\beta\left(1-e^{\frac{-t}{\tau_{2}}}\right)\right]\left[1+\tan h\left(\alpha-\left(\frac{t}{\tau_{3}}\right)\right)\right]
$$

with two parameters $\alpha$ and $\beta$ and three characteristic times $\tau_{1}, \tau_{2}$, and $\tau_{3}$, which are estimated from solidification experimental data. The two characteristic times $\tau_{1}$ and $\tau_{2}$ appear inside the exponential term, which describes the cooling of the sample. They can be related to sensible heat, while the characteristic time $\tau_{3}$ is related to the latent heat.

\section{B. Model parameters}

As can be seen in Figure 6, good agreement was obtained between the experimental data during solidification and the phenomenological expression for a sample of RUB 25. Similar results were obtained for all PPCMs. A complete analysis of all data shows that the parameter $\tau_{2}$ remains constant for the various experiments conducted on the five PPCMs taking into account the same boundary condition (Neumann condition). The results mean that parameter $\tau_{2}$ is independent of both the latent heat $L$ and the temperature interval $\theta_{0}$. This parameter, which characterizes the sensible heat exchanged on the temperature interval $1-\theta_{0}$, takes a value equal to $1.4 \mathrm{mn}$ in the context of our experiment. The influence of boundary conditions, by modifying the convective heat transfer coefficient $h$ between the material surface and air, has not been studied in this work.

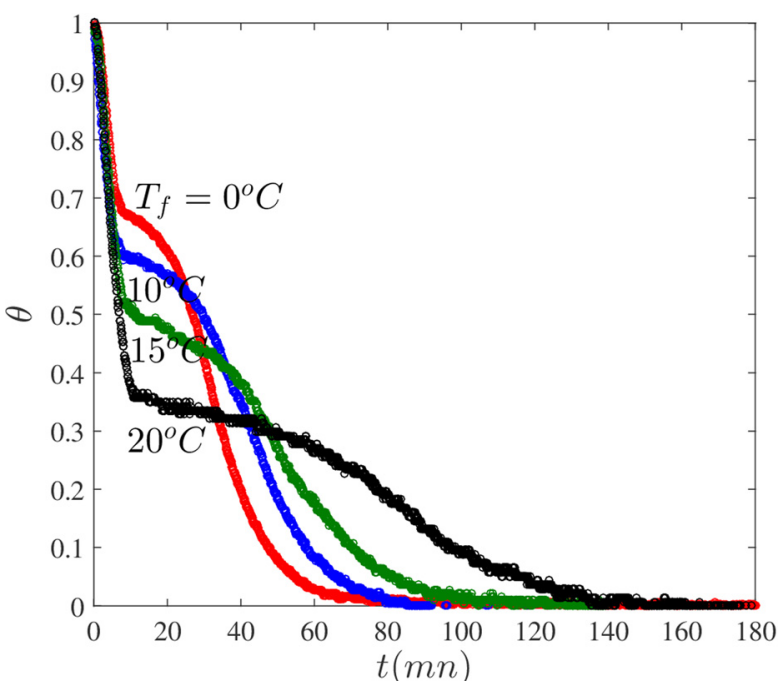

FIG. 7. Thermograms obtained from RUB 25 for $T_{f}=0,10,15$, and $20^{\circ} \mathrm{C}$.
Concerning the parameter $\alpha$, a specific value appears for each PPCM. We note $\alpha=2.5$ for RUB 15, 20, and 25, $\alpha=4$ for HEX 10, and $\alpha=5.5$ for GG 3. This parameter is not affected by the temperature interval $\theta_{0}$. The influence of boundary conditions on this parameter has not been studied in this campaign of experiments.

The variations of the characteristic time $\tau_{1}$ (expressed in $m n$ ) and the inverse of the parameter $\beta$ are shown in Figure 8 as a function of the temperature interval $\theta_{0}$. These two parameters can be expressed in the form

$$
\begin{gathered}
\tau_{1}=2 \theta_{0}^{-1 / 3}, \\
\frac{1}{\beta}=1.4 \theta_{0}^{-1 / 3} .
\end{gathered}
$$

They are related to the sensible heat exchanged by the material in the temperature interval $\theta_{0}$.

The characteristic time, $\tau_{3}$, is the main parameter that affects the length of the phase change pseudo-plateau. It shows a strong dependence with the latent heat $L$ of the material and the temperature interval $\theta_{0}$ as shown in Figure 9.

This time, $\tau_{3}$, can be correlated with the time when the temperature reaches the value of the endset temperature $T_{e}$ defined in the Appendix.

Figure 10 compares the characteristic time $\tau_{3}$ and the time $t_{\text {sol }}$ corresponding to the end of the phase change corresponding to $T=T_{e}$. One can observe a linear relationship between these two characteristic times, which means that the knowledge of the time $\tau_{3}$ gives the value of the complete duration of solidification.

Taking as a time scale the group $\left(E^{2} / a\right)$, we define a dimensionless solidification time from the Fourier number $\mathrm{Fo}_{\text {sol }}$ in the form

$$
F o_{\text {sol }}=\frac{t_{\text {sol }} a}{E^{2}}
$$

with $E$ the sample thickness, $a$ the thermal diffusivity, and $t_{\text {sol }}$ the solidification time.

This analysis can be compared to the analytic approach given by the pioneering work of Neumann who proposed a method to solve the solidification problem in $1 D$ geometry

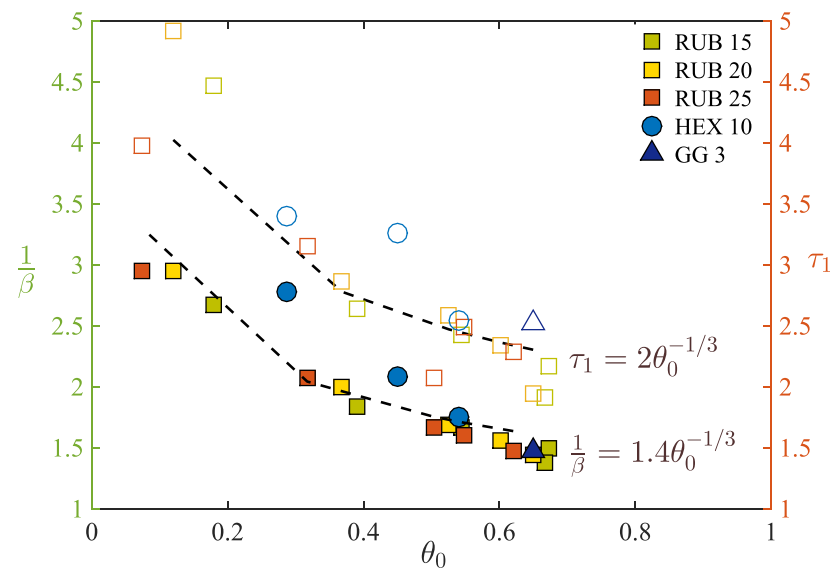

FIG. 8. Variation of the parameters $\tau_{1}$ and $1 / \beta$ as a function of $\theta_{0}$. 


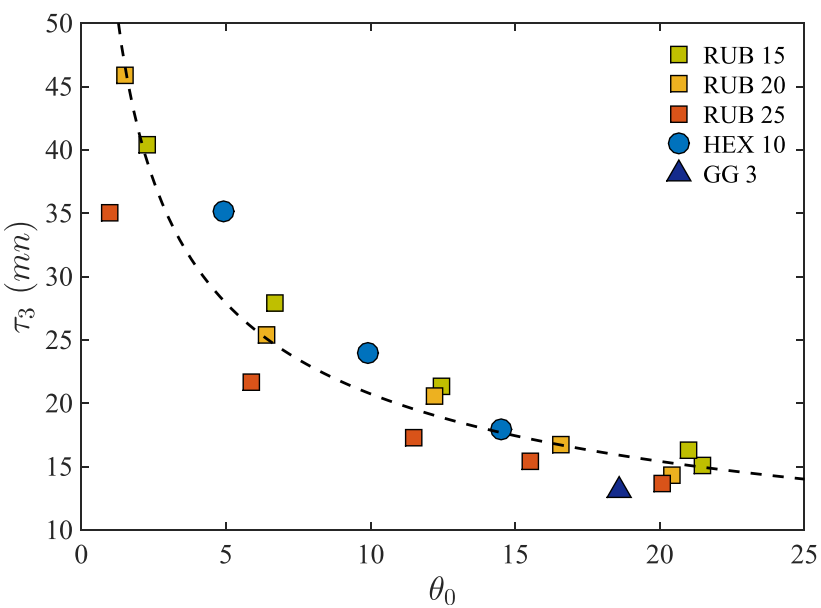

FIG. 9. Variation of $\tau_{3}$ as a function of $\theta_{0}$.

for a semi-infinite solid. ${ }^{9}$ In his work, the material is initially at the phase change temperature, and convection in the liquid phase is neglected, which is compatible with our findings. Considering that temperature profiles in the liquid and solid phases are given by error functions, the energy balance at the liquid/solid interface allows the following equation to be written as

$$
\frac{1 \sqrt{\pi}}{2 \sqrt{F_{O}}} e^{\left(\frac{1}{4 F_{0}}\right)} \operatorname{erf}\left(\frac{1}{2 \sqrt{F_{O}}}\right)=\text { Ste. }
$$

In Equation (7), Ste and $F_{O}$ are the Stefan and Fourier numbers, respectively

$$
\begin{gathered}
\text { Ste }=\frac{C p\left(T_{0}-T_{f}\right)}{L}, \\
F o=\frac{a t}{x^{2}},
\end{gathered}
$$

where $C p$ is the heat capacity, $L$ the solidification latent heat, $t$ the time, and $x$ the position of the liquid/solid interface from the sample surface at time $t$. In this solution, the interface position is a function of the square root of time. The Neumann method has been extended ${ }^{9}$ for different initial and

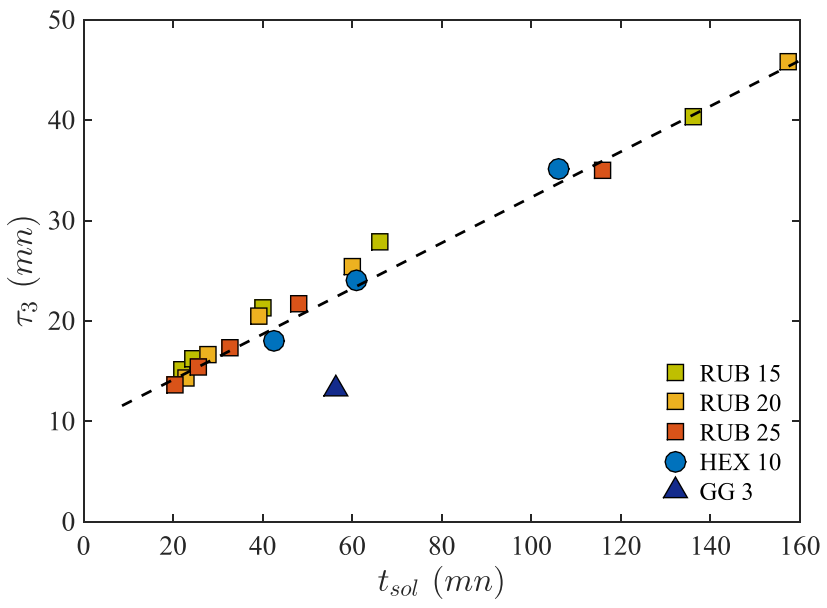

FIG. 10. Variation of $\tau_{3}$ as a function of $t_{\text {sol }}$.

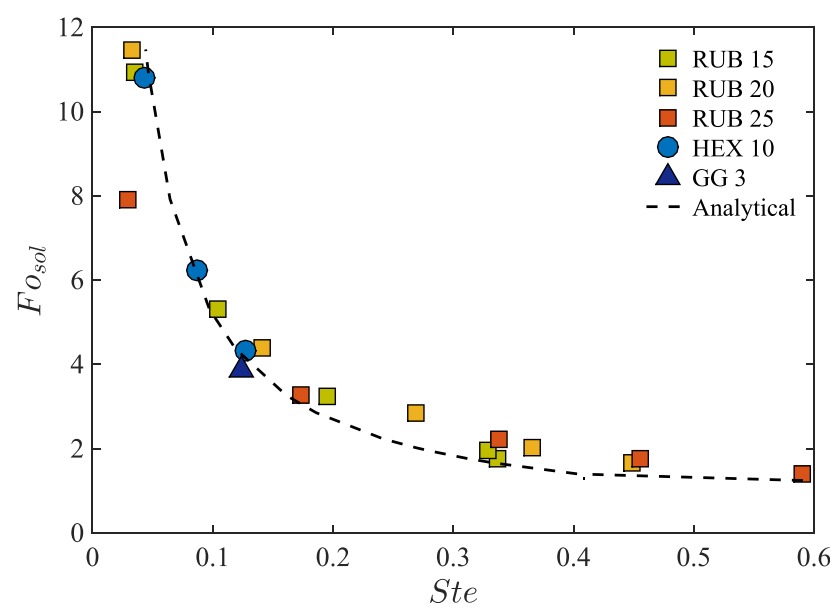

FIG. 11. Dimensionless solidification time from the Fourier number $F o_{\text {sol }}$ as a function of the Stephan number Ste.

boundary conditions. Figure 11 shows the variations of the Fourier number $\left(F_{s o l}\right)$ vs the Stefan number $(S t e)$ for $x=E$. It is shown that the slope is more pronounced for lower Ste than for higher Ste. Experimental results are compared with those from the Neumann formula in Figure 11. We observe good agreement between experimental data and theoretical ones.

The dependence of $F_{O_{s o l}}$ with the Stefan number Ste leads to the following empirical expression:

$$
F o_{\text {sol }}=1+0.4 \text { Ste }^{-1} \text {. }
$$

This result is not far from expressions proposed by Charach and Zoglin ${ }^{10}$ and Charach and Kahn ${ }^{11}$ in the development of a model that combines the heat-balance integral method and the time-dependent perturbation theory. This type of expression depending on $S t e^{-1}$ was also obtained for solidification in cylindrical geometry for several types of boundary conditions. ${ }^{12-15}$

\section{CONCLUSION}

In order to find a thermal energy storage material that can be used practically, we have defined, realized, and characterized PCM/polymer composites. Two paraffins and an aqueous gel were used as PCMs: One paraffin whose melting temperature is about $27^{\circ} \mathrm{C}$ with 3 polymer fractions $(75 \%$, $80 \%$, and $85 \%$ ) and another paraffin whose melting temperature is $18^{\circ} \mathrm{C}$, the polymer proportion is $90 \%$, and an aqueous gel whose melting temperature is $0.7^{\circ} \mathrm{C}$. These PPCMs have a stabilized volume and do not present leaks when the PCM is liquid. To explain this behavior and to analyze the temperature variations, micro- and macro-rheological measurements have been carried out. As an important finding, it was suggested that the heat transfer mode was essentially a conductive heat transfer. To evaluate the melting times, an experimental work was carried out with parallelepipedic samples made of the five PPCMs. The cooling process was studied, and temperature variations at the material bottom were measured. A single phenomenological expression was derived from these temperature variations for the five 
PPCMs. The obtained formula depends on five parameters, one of them giving the pseudo-plateau duration during the melting process. A comparison was made with the Neumann formula, which only considers heat conduction both in the liquid and in the solid state. A very good agreement was obtained, validating the hypothesis of pure heat conduction in this type of materials. This phenomenological expression can be used for rapid evaluation of temperature variations in cooling processes of parallelepipedic composites.

\section{ACKNOWLEDGMENTS}

The authors gratefully acknowledge the Île-de-France region (VEGETO Project, Contract No. 14011077) for the financial support.

\section{APPENDIX: THERMODYNAMICAL PROPERTIES OF PCMs}

The calorimetric measurements were carried out with a DSC (differential scanning calorimetry) instrument (Mettler Toledo). Indium was used as the standard reference for the calibration. The samples were sealed in aluminium pans, with the masses being typically few $10 \mathrm{mg}$ for all the samples. Both heating (melting) and cooling (crystallization) curves were registered between $278 \mathrm{~K}$ and $348 \mathrm{~K}$ with a linear temperature increase of $1 \mathrm{~K} / \mathrm{mn}$. As further explained below, transition temperatures, enthalpies of transition, and specific heats were obtained from the analysis of experimental DSC curves.

An example of a typical thermogram, obtained here for the RUB 25 material, is presented in Figure 12. The curves show a classic exothermic peak on cooling and an endothermic peak on heating. The latent heat $L$ is calculated by numerical integration of the area under the peaks that represent the phase change transition. Two transition temperatures, namely, the temperature at the peak of the curves noted $T_{m}$ for melting and $T_{s}$ for solidification, are found. In this study, we have also considered the endset temperature as $T_{e}$, which is measured by drawing a line at the point of the maximum slope of the leading edge of the end peak and concluding at the baseline.

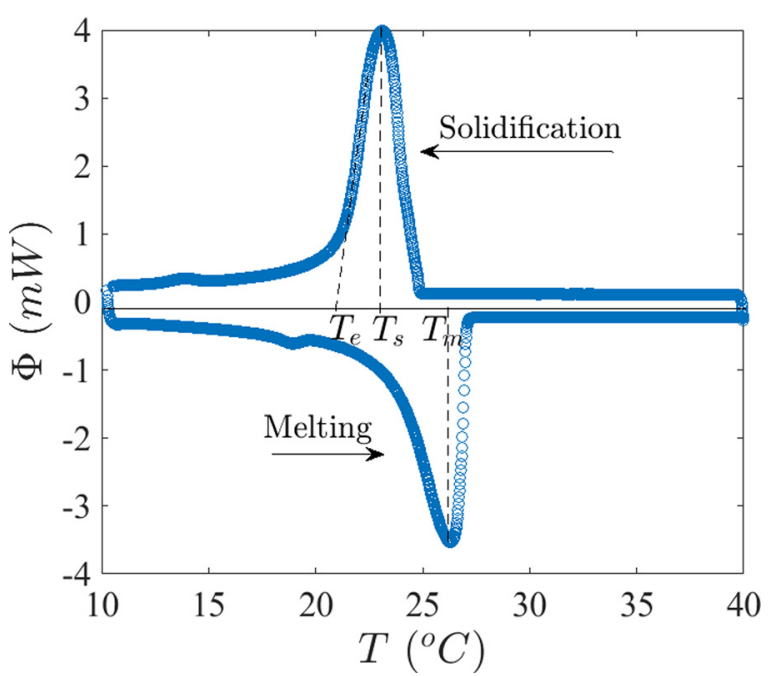

FIG. 12. Thermogram of RUB 25 for a heating/cooling rate of $1^{\circ} \mathrm{C} / \mathrm{mn}$.

Experimental data are reported in Table I. The values are an average obtained for three runs for each sample. The specific heat capacity values $C p$ are taken for the temperature ranges that appear almost flat in experimental data plots.

${ }^{1}$ D. Lefebvre and F. H. Tezel, Renewable Sustainable Energy Rev. 67, 116-125 (2017).

${ }^{2}$ N. Calvet, X. Py, R. Olivès, J.-P. Bédécarrats, J.-P. Dumas, and F. Jay, Energy 55, 956-964 (2013).

${ }^{3}$ W. Su, J. Darkwa, and G. Kokogiannakis, Renewable Sustainable Energy Rev. 48, 373-391 (2015).

${ }^{4}$ T. Khadiran, M. Z. Hussein, Z. Zainal, and R. Rusli, Sol. Energy Mater. Sol. Cells 143, 78-98 (2015).

${ }^{5}$ J. Wang, H. Xie, Z. Xin, Y. Li, and C. Yin, J. Appl. Phys. 110, 094302 (2011).

${ }^{6}$ P. Zhang, X. Xiao, and Z. W. Ma, Appl. Energy 165, 472-510 (2016).

${ }^{7}$ S. A. Bahrani, Y. Jannot, and A. Degiovanni, J. Appl. Phys. 116, 143509 (2014).

${ }^{8}$ R. Colin, A. Al-Sayed, J.-C. Castaing, R. Goyal, L. Hough, and B. Abou, Soft Matter 7, 4504 (2011).

${ }^{9}$ H. S. Carslaw and J. G. Jaeger, Conduction of Heat in Solids, 2nd ed. (Oxford University Press, 1959).

${ }^{10} \mathrm{Ch}$. Charach and P. Zoglin, Int. J. Heat Mass Transfer 28, 2261-2268 (1985).

${ }^{11}$ Ch. Charach and P. B. Kahn, J. Appl. Phys. 59, 3579-3581 (1986).

${ }^{12}$ A. D. Solomon, Sol. Energy 22, 251-257 (1979).

${ }^{13}$ V. Voller and M. Cross, Int. J. Heat Mass Transfer 24, 545-556 (1981).

${ }^{14}$ A. Hasan, Sol. Energy 52, 143-154 (1994).

${ }^{15}$ D. S. Riley, F. T. Smith, and G. Poots, Int. J. Heat Mass Transfer 17, 1507-1516 (1974). 